\title{
The Ontological Roots of Temporality
}

\section{Abstract}

In order to revisit the question of the nature of time in the context of the present volume, it is advisable to probe successively the following issues. 1 . What is time, respectively for philosophy, science, and technoscience? 2. How have its foundations been shaken by Einstein's relativities, Bergson's duration and Whitehead's creative advance? 3. What are the available data? 4. What method should one use to make sense out of them? 5. What is the outcome of their processualization? In conclusion, we highlight the threefold root of temporality disclosed in Whiteheadian organicism

\section{What is Time?}

The question of the nature of time is as old as philosophy itself - but not older. This means that, before philosophy, time was not problematized, it was a pure common-sensical matter. There were various experiences of time, and, accordingly, different words to name it. The factual was simply not problematical. At most, time was probed in mythological narratives, and anthropomorphized (or divinized) accordingly.

As a matter of fact, philosophy did not spring out of a vacuum and some ancient patterns of thought have endured: Greek culture was, to simplify, both mythological and political. (The very first simplification that this paper brings about is the bracketing of the philosophy, lato sensu, of other cultures. India and China come to mind, of course, but there is no a priori reason to ignore the philosophies of life of Africans or Amerindians...) Hence the two main philosophical sub-territories: metaphysics and politics, each being intertwined with epistemology and ethics. More precisely, philosophy has always had a scientific tropism. Hence the need to provide such a definition of time, and to take it seriously. In other words, as Augustine claimed, as long as one does not worry about the exact nature of time, there is no problem whatsoever (Augustine, Confessions, 397-398, II, 14-20). But if (when) you do, Pandora's box flips wide open. Does time belong to things, to events, to the (human) spectator? What is the political time, the time of action, the time of debate, the time of solitude? Do we have any knowledge of time that could be injected in these metaphysical and political is- 
sues? Doesn't ethics presuppose time insofar as, without liberty, there is neither time nor ethical action?

When addressing the question of time, one has first to acknowledge that there are various experiences of time, and many ways to name them; e.g., in Greek: chronos, aiôn, aidion, kairos, horai... These concepts, that sometimes overlap, name various facets of time: physical, cosmological, psychological, linear, circular, rhythmic, pragmatic, destinal (the life-time), qualitative and quantitative. Past, present, and future have distinctive traits. ${ }^{1}$ The past is extended, horizonal; the present seems timeless, perhaps point-like; the future is nothing but a virtual tension. If you obliterate some of these experiences, and especially if you consider that time has to be quantified, you open the floodgates to all the contradictions and paradoxes that have haunted the Western mind for centuries. This is, precisely, what philosophy has done first, science later, and theology in the meantime. The subsidiary question is thus: what, if anything, is gained by the theoretical tropism inaugurated by philosophy, endorsed by science, and pushed to the hilt by technoscience? For the sake of analysis, let us briefly peruse, respectively, time in philosophy, time in science, and time in psychology. In order to obtain a panoramic view of the history of ideas, it makes sense to “seek simplicity and distrust it” (Whitehead 1964, 163).

\subsection{Philosophy}

To define philosophy and to specify what it is all about is a serious matter. Lato sensu, philosophy embodies the quest for the meaning of life, and especially probes the harmony that exists, used to exist, or could exist, between humans and their world. ${ }^{2}$ Since it is a quest, it should not pretend to be able to provide dogmatic answers. Since it tends towards universal harmony, it can nevertheless focus on the notion of wisdom. Stricto sensu, philosophy amounts to the shift

1 See Eugène Minkowski’s landmark Bergsonian study. See Minkowki (1970).

2 "The two positive Socratic propositions read as follows. The first: 'It is better to be wronged than to do wrong', to which Callicles, the interlocutor in the dialogue, replies as all Greece would have replied, 'To suffer wrong is not the part of a man at all, but that of a slave for whom it is better to be dead than alive, as it is for anyone who is unable to come either to his own assistance when he is wronged or to that of anyone he cares about'. The second: 'It would be better for me that my lyre or a chorus I directed should be out of tune and loud with discord, and that multitudes of men should disagree with me rather than that I, being one, should be out of harmony with myself and contradict me'. Which causes Callicles to tell Socrates that he is 'going mad with eloquence' and that it would be better for him and everybody else if he would leave philosophy alone” (Arendt 1978, 180-181). 
from mythos to logos, and this required, and fostered, a new political venture: direct democracy, with its founding principles -isonomia (all are equal before the law) and isègoria (all have the equal right to address the political assemblies) - and its core institutions (ekklêsia, the assembly of all citizens; boulê, the council of the 500; heliaia, the supreme court...). Human beings belong to the world; the human logos is the same as the natural logos...

Hence the following three important conceptual thresholds: Plato, Aristotle, and Plotinus. Before Plato, one can only guess what has been achieved conceptually; Plato himself "moves about amid a fragmentary system like a man dazed by his own penetration" (Whitehead 1967a, 147). Aristotle is, arguably, the first philosopher to hierarchize the concepts of time, focusing on chronos, giving to the aiôn a supralunar status, and reducing the kairos to a subsidiary, anthropological, matter. We recognize time when we distinguish movement, he claims, which we do by "before and after" (Aristotle, Physics, 219a22 sq). Plotinus reconsidered this classification and argued that Kairos belong to the first hypostasis, aiôn to the second, and chronos to the third. Stretching these concepts a bit leads to Trinitarian theology, that secures chronological time (i.e., time qua chronos), since it is created with the world and will end with it. Mutatis mutandis, Whitehead will provide a Plotinian ontology of time (see our $\S 5.3$ ).

\subsection{Science}

Although common sense is perfectly able to deal with the weaknesses and contradictions of sense perception, science doubles down, so to speak, the philosophical bet, and is not afraid of creating as much epistemological problems as it allegedly solves. While philosophy, per se, has, sometimes reluctantly, kept the systematic relevance of qualia, on the contrary, science, per se, is defined by the quantification and the mathematisation of the world. Its founding moment takes place when the experimental protocol (a necessary, intellectual, perception of sorts) substitutes itself for observation (sensible perception and its contingent trail of aberrations, errors and misinterpretations) in Galilei's Discorsi (1638).

When Galilei writes "mente concipio" he operates an epistemological Uturn. What we observe does not really matter anymore; we have to put nature to the question. Galilei's starting point is resolutely anthropocentric (but not anthropomorphic): I conceive in my mind of something moveable that is entirely left to itself; I conceive in my mind of a body thrown on an infinitely extended horizontal plane... (Galilei 1638; Heidegger 1967). The power of imagination ac- 
quired then a scientific relevance that is still actual (remember, e.g., Einstein's photonic ride).

The consequences on the notion of time are remarkable. Time becomes, in the Greek lexicon, purely chronological. Since without measuring instruments, the notion of linear (physical) time is of course difficult to use, it could be argued that scientific progress is entirely dependent upon the availability of reliable clocks and rods. Moreover, clocks and rods are, in themselves, pretty much useless: a universal metrics is needed, and this involves a more or less explicit ontology of space and time. (A more sophisticated approach involves a philosophy of perception unfolding the conditions of possibility of measurement: that task is left to philosophy).

Newton's physics (and one should remember that Newton has apparently spent most of his life practicing alchemy rather than physics ${ }^{3}$ ) solved the metrical conundrum very elegantly: time and space are absolute, they constitute the divine organ of perception (sensorium dei). Past and future are perfectly symmetrical for the divine mechanics. This move is the root of Kant's Transcendental Idealism: time is a condition of experience, not one of its by-products. Time flows uniformly, independently of what happens, or not.

This being said, although science departs from philosophy in its strict mathematisation and experimental protocol, it largely keeps the philosophical deontology and works towards the common good.

\subsection{Technoscience}

On the contrary, technoscience is purely utilitarian, and this gives a different flavour to Kant's definition of the Enlightenment. The motto "Have courage to use your own reason!” (“Sapere aude!”), instead of urging man's release from his self-incurred tutelage (Kant 1996) names now the shift from a theological, dogmatic, reason, to an anthropological, but equally dogmatic, reason. Theology was of course alienating, but it kept some room for the opacity of experience and the mystery of life. With the Enlightenment, a total (scientific) transparency of experience is supposed to be reachable. Of course, Kant himself repeatedly tried to salvage whatever he could of the scraps of meaning ignored by scientific

3 Newton (Philosophiae naturalis principia mathematica, 1687) is only the tip of the iceberg: according to Keynes, who explored the unpublished works of Newton in the years 1942-1946, the most influential scientist was (also) an avid alchemist, "the last of the magicians". Newton's alchemical research made him prone to embrace pantheism. 
reductionism; he certainly convinced most his readers, but did he persuade them? ${ }^{4}$

"Technoscience” ("TechnoWissenschaft” in German) is a concept framed by Habermas (1968) and refined by Hottois (1984), among others. It is used here in order to point at the mutual transformation that has progressively taken place between science and technology. ${ }^{5}$ With the industrial revolution (that flourished circa 1830, if one takes the generalization of the use of coal as criterion), science has more and more been lured by its practical consequences, and since these have been increasingly commercial, it should be plain obvious that the synergy at work has benefited mainly to capitalists. Better: neither science nor technology has ever been axiologically neutral. Technoscience is actually a ménage à trois! In practice, this means that the project of mastering nature (remember Bacon, Vico and Descartes), ${ }^{6}$ that, at one point, could pretend to be neutral (but what is the exact link between theôria and episteme in Plato? And how did Newton manage both his alchemical quest and his mechanistic worldview?) has become the capitalistic urge to bend culture: to know the world, one must first manufacture it.

On the one hand, measurement, and especially time measurement, is essential for technoscience. So much so that scientific progress is entirely dependent upon the availability of reliable clocks and rods. Historically speaking, the first places where time was mastered in order to manufacture the world were Catholic monasteries. ${ }^{7}$ Technology, such as sophisticated clocks, solves practical issues, of course, but it also creates new practical and theoretical problems. ${ }^{8}$ With the rapid expansion of the use of the electrical telegraph in the mid19 ${ }^{\text {th }}$ century, simultaneity became an urgent issue. Is the time of the transmitter the time of the receiver? If not, what inertial system can we use to tune in both sides? On the other, Bergsonian, hand, psychological time has two main modalities. Lato sensu, it refers, first, to lived time qua duration, and, second, to the cosmic living

\footnotetext{
4 A logical argument is supposed to convince the third party, but this does not mean that s/he will act accordingly; if one sets an example, the third party can be persuaded, and follow up in practice.

5 A distinction should be made between technics and technology, tools and machine.

6 According to, e. g., Francis Bacon (Meditationes Sacrae, 1597), Giambattista Vico (De antiquissima Italorum sapientia, ex linguae latinae originibus eruenda, 1710) and René Descartes (Discours de la méthode, 1637), knowledge itself is power, and, more precisely, power to become the masters and possessors of nature.

7 See Musso (2017).

8 To give contemporary exemplifications: how do you decommission nuclear power plants? How to dispose of the nuclear waste? How do you deal with the scarcity of resources, especially of rare earths?
} 
time of the élan vital. Stricto sensu, it belongs to the science that emerged in the years 1875-1879, when Wundt was appointed to the chair of psychology in Leipzig Universität, where he opened the first laboratory of experimental psychology. Psychophysics became strongly anchored in academia; it is still there (Wundt 1896). Relativity only exacerbates the existing stakes.

To boil it down to the basics, time is now money. This is, so to speak, the price to pay for the gospel of efficiency.

\section{Shaking the Foundations}

With this broad horizon in mind, we can revisit the rationale for the What is time? Einstein and Bergson 100 years later conference held in the Università degli Studi dell'Aquila in April 2019. A meaningful parallel was indeed made between the April 6, 2009's earthquake and the April 6, 1922's cultural quake.

\subsection{April 6, 2009's Earthquake}

Earthquakes constitute first-rate traumatic events. Clinically, a trauma is an event during which one's life is threatened, or during which one watches somebody else's life endangered. As a consequence, the victim is likely to suffer from PTSD, making life difficult, or even unbearable. ${ }^{9}$

Philosophy provides broader concepts to circumscribe the consequences of earthquakes. They underline the stability that we always take for granted in everyday experiences. Body and ground are presupposed in all experiences. If the body is attacked-traumatized-, or if the ground gives way beneath us, we lose our vital confidence and life becomes a meaningless burden. Five complementa-

\footnotetext{
9 "The essential feature of Posttraumatic Stress Disorder is the development of characteristic symptoms following exposure to an extreme traumatic stressor involving direct personal experience of an event that involves actual or threatened death or serious injury, or other threat to one's physical integrity; or witnessing an event that involves death, injury, or a threat to the physical integrity of another person; or learning about unexpected or violent death, serious harm, or threat of death or injury experienced by a family member or other close associate (Criterion A1). The person's response to the event must involve intense fear, helplessness, or horror (or in children, the response must involve disorganized or agitated behaviour) (Criterion A2)" (DSM-IV-TR 1994, §309.81). A hundred years ago, however, hysteria was the trendy clinical tool. While, in the popular literature, PTSD is the concept attached to veterans' impossibility to enjoy life after their mission, hysteria named, first, the state in which rape and incest leave children, and, second, an unsolved Edipus complex.
} 
ry concepts are outstanding, and each would deserve a paper of its own: Husserl's Ur-Doxa (Die Urarche Erde bewegt sich nicht, 1934), Santayana's instinctive faith (Scepticism and Animal Faith, 1923), Tillich's ontological security (The Courage to Be,1952), Merleau-Ponty's perceptive faith (Le Visible et l'invisible, 1964), Arendt's Common-sense qua three-fold commonness (The Life of the Mind, 1978). All spell in their own way that life requires that we fundamentally believe not only in the cosmic harmony of all things (hence in permanent rules which underlie all events), but also in their duration. If the cosmic unity and stability is falsified by experience, anxiety prevails ever after.

\subsection{April 6, 1922’s Cultural Quake}

Rhetorically speaking, it makes sense to draw a parallel between the loss of ontological security due to an earthquake, and the disarray following the destruction of human temporality by some well-known Nobel prize winner. ${ }^{10}$ The meeting between Einstein and Bergson is usually understood as the turning point of Bergson's fame, but its consequences were far deeper: it meantand still means that science's symbolic violence was powerful enough to make (some) people renounce to their own experience, and to prefer a construct condemning their life to meaninglessness. ${ }^{11}$ This is also, by the way, the significance of Watson's $B e$ haviourism (1928). Three points are important to make.

If time is only a matter to be quantified by, and for, technical contraptions, and, especially, if time must be interpreted as a purely contingent feature of our subjectivity, what happens between birth and death is anecdotal and insignificant, which means, first, that basic common sense is obliterated. When Einstein, in 1955, writes to Michele Besso's widow that his death doesn't mean much because for people who believe in physics the distinction between past, present and future is only a stubbornly persistent illusion, he tries to make sense of death by denying the possibility of life, and of meaning. Moreover, what sort of science

10 Einstein received the 1921 Nobel Prize in Physics for his discovery of the law of the photoelectric effect. Bergson was awarded the 1927 Nobel Prize in Literature.

11 "La violence symbolique, c'est cette violence qui extorque des soumissions qui ne sont même pas perçues comme telles en s'appuyant sur des 'attentes collectives', des croyances socialement inculquées. Comme la théorie de la magie, la théorie de la violence symbolique repose sur une théorie de la croyance ou, mieux, sur une théorie de la production de la croyance, du travail de socialisation nécessaire pour produire des agents dotés des schèmes de perception et d'appréciation qui leur permettront de percevoir les injonctions inscrites dans une situation ou dans un discours et de leur obéir” (Bourdieu 1994, 188). 
requires belief? Second, the meaning of life disappears for the simple reason that time and action are correlated. If action, in the ethical and political sense, is not possible, we live in a purely deterministic universe where no change is possible. There is neither ethics, nor politics, nor psychotherapy possible because at best we can only shoulder pseudo-decisions made by the universal Logos or the local Chaos. Third, the interplay between science and philosophy becomes an empty set. Real philosophers are scientists -but real scientists are not philosophers...

\subsection{Bergson's Duration \& Whitehead's Creative Advance}

To some extent, coping with the consequences of an earthquake amounts to be able to deal with the symbolic violence we have just introduced. In other words, the reconciliation of the human temporality with natural time is not an idle hobby, but an urgent task in societies that are shot through and through by technoscience.

What is time? Our personal experience of time imposes itself upon all scholarly debates, metrics, rods and clocks: not only does it make sense in and of itself, but it is also presupposed by all scientific protocols. Exactly, philosophers such as James, Bergson or Whitehead sought a worldview that would explain the successes of science without denying the specificities of our human existence. As a result, they provided categories that are more powerful (i.e., more coherent and applicable) than the scientific concepts shrinking the depth of our experience.

In order to contrast Einstein's physical, measured, time, with Bergson's lived, qualitative, time, we can benefit from Whitehead's own scientific expertise and philosophical intuition (no pun intended, but appropriate). In Duration and Simultaneity (1922), Bergson remarks indeed that there is no real conflict between science and philosophy as soon as one admits the reality of the creative advance of nature - a concept framed by Whitehead in An Enquiry Concerning the Principles of Natural Knowledge (1919). ${ }^{12}$ Here is how he sketches it one year later:

12 "We thus kept as close as possible to the immediate; we asserted nothing that science could not accept and use; only recently, in an admirable book, a philosopher-mathematician affirmed the need to admit of an 'advance of Nature' and linked this conception with ours” (Bergson 1965, 62; Whitehead 1964, 54). "This work (which takes into account the theory of Relativity) is certainly one of the most profound that has been written on the philosophy of nature" (Bergson 1965, 62 ff1). 
The difficulty as to discordant time-systems is partly solved by distinguishing between what I call the creative advance of nature, which is not properly serial at all, and any one time series. We habitually muddle together this creative advance, which we experience and know as the perpetual transition of nature into novelty, with the single time series which we naturally employ for measurement. The various time series each measure some aspect of the creative advance, and the whole bundle of them express all the properties of this advance which are measurable. The reason why we have not previously noted this difference of time-series is the very small difference of properties between any two such series (Whitehead 1964, 178).

When he addresses Einstein's Relativity, Whitehead hammers basically one point: although Einstein denies the uniformity of space-time, his equations and any experimental protocol presuppose the independence and uniformity of space-time. We have to take into account our ordinary sense experience. In order to understand the meaning and significance of Whitehead's creative advance, it is expedient to remind the reader of the wealth of data involved, and of the method used.

\section{Data: Radical Empiricism}

What are exactly the data of speculative philosophy? Clear and distinct ideas? Scientific facts? Bare sense-perceptive evidences? Common sense beliefs? Whitehead, who scrupulously adopts the radical empiricism which pedigree was established by James, accepts them all, but not always at face value. In sum: philosophy has to accept all experiences but only experiences. This corresponds to James' Principle of Pure Experience. "Only experiences” means that our total experience is the sole purveyor of evidences. Anything that is not experienced has no relevance for speculative philosophy. Of course, this requirement has to be taken cum grano salis: in the course of his/her argument, the philosopher necessarily introduces abstractions that "makes a flight in the thin air of imaginative generalization" (Whitehead 1978, 5).

As we will shortly see, the point is to make sure these generalizations aim at the concrete experience, that they are not swallowed by a purely conceptual organism pretending, like Kant's dove, to ignore its cosmic roots and by-products in order to foster higher degrees of consistency and of coherence (applicability and adequacy are foreign categories in this case). "All experiences" means that basically three layers of evidence should testify during our enquiry concerning the principles of natural knowledge: exteroception, the withness of the body, and exceptional mental states. 


\subsection{Exteroception}

$A b$ Jove principium, sense-perception (i.e., exteroception, which is constituted by the five senses open to the external world) has to play a major role in our data gathering. But our appraisal of its potential should not be naïve: Whitehead, following the empiricist tradition (especially Berkeley, Locke and Hume) insists on the limitedness and possible misleadingness of exteroceptive data. They certainly provide a clear and distinct picture of our immediate surroundings, but they do so by ignoring details and especially by bifurcating the perceiving subject and its environment and by neutralizing time and causation. More precisely, Whitehead underlines the (ab)use philosophy has made of the metaphor of vision, that has imposed the idea of the spectator-subject, i.e., of a totally passive onlooker factually unaffected by the scenery. Hans Jonas, probably under the spell of Whitehead, has shown very straightforwardly the inevitable bias of the concept of theoria (Jonas 1966).

\subsection{The Withness of the Body}

Sense perception is actually a very simplified (though sophisticated) projection established on the wealth of data in which the subject is immersed -better, that constitutes the subject. A first step towards these roots is made by considering interoceptive and proprioceptive data, that both occur at the fringes of our normal state of consciousness.

Interoception names the internal sensitivity complementing the exteroceptive one. Its messages, coming from receptors housed by all organs and tissues, are, through reflex (i.e., non-conscious) action, the source of a harmonious bodily life. One can distinguish internal pains (cephalalgia, colic...), internal taste (chemical sensitivity ruling various reflex activities), and internal touch (sensitivity to variations of pressure, like distension of the bladder or the rectum, stomach contractions, antiperistaltic contractions of the œsophagus, determining the nausea feeling). ${ }^{13}$

Proprioception names the messages of position and movement allowing, with the help of the internal ear's semi-circular canals a spatialization-i.e., a full (ap)propriation-of the body. Proprioceptive perception grows from sensorial

13 Bergson alludes to these messages when he speaks of "the sensations of 'internal touch' emanating from all points of the organism and, more particularly, from the viscera" (Bergson 1920, 111). 
receptors ${ }^{14}$ delivering data about the position and the relative movements of the different parts of our body. Through reflex action, it regulates the muscular tone and helps us to localise ourselves in space and to create a sense of depth (stereognosy). Proprioception also includes the muscular sensitivity that complements exteroceptive touch in offering estimates on the weight and volume of the prehended and/or moved object. The structuration of our proprioceptive field provides for the fundamental organic anchorage of our identity.

Whitehead's withness of the body (Whitehead 1978, 81; 312; 333) can be said to emerge out of the togetherness of all three of these perceptive modes, internal as well as external. Hence the motto and starting point for philosophers should be "meditate on your viscera". ${ }^{15}$ An important consequence for the consciousness of time is that, in the everyday, 'normal' state of consciousness, we live in the past, simply because all the data take time to arrive at our senses, to be conveyed through the central nervous system, and to be synchronized by the brain. $^{16}$

\subsection{Exceptional Mental States}

There remains however a third cognitive field that has been scrutinized, a bit shyly, by Whitehead's Religion in the Making (1926) and explored, this time extensively, by James' Varieties of religious experience (1902) and Bergson's Les deux sources de la morale et de la religion (1932): the altered states of consciousness that pave the way to mysticism (James' first-hand religious experiences) and thereby ground religion itself (second-hand religious experience). At the fringes of the Mediterranean beauty of exteroception lays not only the cognitive and emotional vagueness of the withness of the body but also, beyond it, the religios-

14 Articular capsule, periosteum, tendons, joints, muscles house sensitive corpuscles and nerve endings similar to the skin's one. See Sherrington 1940, 309; Sherrington 1947, 132-133.

15 "Over the door of Emerson Hall, the Philosophy Building at Harvard, there is an inscription. I have quite forgotten what it is; I only remember that it is something very high-minded. Whitehead said to his class, "You will have noticed that motto over the door. I commend to you as a more suitable motto and starting point for philosophers 'Meditate on your viscera'. He insisted that philosophers have disdained the information about the universe obtained through their visceral feelings, and have concentrated on visual feelings" (Emmet 1948, 265-274). The inscription over the door is from the Bible, Psalm 8, reads: "What is man that Thou art mindful of him?” The Philosophy faculty chose a quotation from Protagoras: "Man is the measure of all things". Harvard President Charles William Eliot, substituted the biblical passage without consulting with the faculty.

16 See Pöppel (1988). 
ity's Dark Night, during which one embraces the void and its heirs (nihil videt et omnia videt).

\title{
4 Method: Imaginative Generalization
}

Whitehead recommends the method of imaginative generalization, that he sketches as the flight of the aeroplane; but who is Whitehead, and why does he matter?

\subsection{Whitehead, the Post-Modern Plato}

Whitehead (1861-1947) can be said to be the post-modern Plato for two complementary reasons. On the one hand, like Plato he has studied, taught, and contributed to all the science of his time, from Algebra to Natural theology. Also, he has created a unified, coherent and applicable worldview, mainly in Process and Reality. An Essay in Cosmology (1929). His main sources of inspiration were common sense, algebra, Maxwell's field concept (1873), Spencer (1855), and Darwin (1859). On the other hand, unlike Plato, he gave a positive ontological status to the accident, the event. Whitehead is concerned with the sumbebekos. According to his process-organic philosophy:

\begin{abstract}
We are accustomed to associate an event with a certain melodramatic quality. If a man is run over, that is an event comprised within certain spatiotemporal limits. We are not accustomed to consider the endurance of the Great Pyramid throughout any definite day as an event. But the natural fact which is the Great Pyramid throughout a day, meaning thereby all nature within it, is an event of the same character as the man's accident, meaning thereby all nature with spatiotemporal limitations so as to include the man and the motor during the period when they were in contact (Whitehead 1964, 75).
\end{abstract}

\subsection{The Flight of the Aeroplane}

What does the metaphor of the flight of the aeroplane means? Whitehead writes

The true method of discovery is like the flight of an aeroplane. It starts from the ground of particular observation; it makes a flight in the thin air of imaginative generalization; and it again lands for renewed observation rendered acute by rational interpretation. [...] The success of the imaginative experiment is always to be tested by the applicability of its results beyond the restricted locus from which it originated. In default of such extended application, a generaliza- 
tion started from physics, for example, remains merely an alternative expression of notions applicable to physics. The partially successful philosophic generalization will, if derived from physics, find applications in fields of experience beyond physics. It will enlighten observation in those remote fields, so that general principles can be discerned as in process of illustration as in process of illustration, which in the absence of the imaginative generalization are obscured by their persistent exemplification (Whitehead 1978, 5).

Two consequences are important: first, philosophy does not amount to what is often called the "philosophical culture". Philosophy should not be understood, and especially not be taught, as an historical or a cultural discipline. Qua history, it unfolds legacies (Kant is the heir of Aquinas, who read Augustine, who understood the consequences of the contrast between Plato and Aristotle, etc.); qua culture, it weaves concepts (matter and form belong together; together they are likely to require some demiurge to secure their interplay; that demiurge might have a benevolent agenda - or not, etc.) Philosophy is anchored in experience and, when it has sharpened its concepts, they should return to experience to be put to the test.

Second, the data are both immediate and mediate. On the one hand, all the experiences of a given individual-whether they are exteroceptive, proprioceptive, interoceptive, or exceptional- could bring relevant generalizations. This is the radical empiricist wager: nothing can be omitted, experience drunk and experience sober, experience sleeping and experience waking... ${ }^{17}$ Hence the intrinsic opacity of the world for the human rationality: "You think the world is what it looks like in fine weather at noon day; I think it is what it seems like in the early morning when one first wakes from deep sleep" (Russell 1956, 39). ${ }^{18}$ On the other, scientific experiments and theories are also eligible. If sci-

17 "In order to discover some of the major categories under which we can classify the infinitely various components of experience, we must appeal to evidence relating to every variety of occasion. Nothing can be omitted, experience drunk and experience sober, experience sleeping and experience waking, experience drowsy and experience wide-awake, experience self-conscious and experience self-forgetful, experience intellectual and experience physical, experience religious and experience sceptical, experience anxious and experience care-free, experience anticipatory and experience retrospective, experience happy and experience grieving, experience dominated by emotion and experience under self-restraint, experience in the light and experience in the dark, experience normal and experience abnormal" (Whitehead 1967, 226; James 1950, 232).

18 Russell adds: "I thought his remark horrid, but could not see how to prove that my bias was any better than his. At last he showed me how to apply the technique of mathematical logic to his vague and higgledy-piggledy world, and dress it up in Sunday clothes that the mathematician could view without being shocked. This technique which I learnt from him delighted me, 
ence points at a problem of simultaneity, philosophy should help contextualizing the stakes.

\subsection{The Reformed Subjectivist Principle}

All this presuppose what Whitehead calls the "Reformed Subjectivist Principle", that is, and is not, subjectivist. Some form of subjectivism is of course assumed: all experiences point at the existence of a subject. But that subject is made out of these experiences, it does not pre-exist them. Moreover, subjectivity is not limited to the human, or even the animal, realm. Everything that exists experiences. We end up with a very sophisticated and critical form of panpsychism (James'“Pure Experience" or Russell's "Neutral Pluralistic Monism"), and, in order to avoid misunderstandings, it makes sense to talk about a "Pan-Experientialism" (Griffin 1977).

\section{Outcome}

Let us now specify Whitehead's solution of the temporal conundrum. Since I have already extensively treated this ontological issue (Weber 2016) while Desmet (2010a; 2010b) has provided a detailed discussion of Whitehead's Relativity itself, ${ }^{19}$ I propose here only a broad framework.

\subsection{Examining the Foundations}

Whitehead's very first move is to understand time in the same way he treated space, relationally. Here is what he wrote to Russell in 1911:

Last night [...] the idea suddenly flashed on me that time could be treated in exactly the same way as I have now got space (which is a picture of beauty, by the bye). [...] The result is a relational theory of time, exactly on four legs with that of space. [...] It gets over all the old difficulties, and above all abolishes the instants in time, e.g., the present instant, even in the shape of the instantaneous group of events. This has always bothered me as much as the 'point' [...]. According to the theory, the time-relation as we generally think of it (sophis-

and I no longer demanded that naked truth should be as good as the truth in its mathematical Sunday best” (Russell 1956, 39).

19 Desmet especially underlies the significance, of Minkowski, Silbertein and Cunningham, for the special theory, and of de Sitter and Eddington, for the general theory. 
ticated by philosophy) is a great cook up. Simultaneity does not belong to it. That comes in from the existence of the space-relation. Accordingly, the class of all points in space serves the purpose of the instant in time. Also each object runs its own time (properly so-called) (Russel 1985, 299).

There is a breakthrough, but it is not total. On the one hand, instants of time are abolished, relationality instituted, and this paves the way to Relativity. On the other hand, Whitehead will soon realize that it makes little sense to treat time like space... His 1925 Lowell Lectures, later published, with three additional crucial chapters as Science and the Modern World, provides the point of inflection. The fourth chapter offers, indeed, a key discussion of Whitehead's argument against mechanicism: he depicts here the ins and outs of "Simple Location", a major instantiation of his "Fallacy of Misplaced Concreteness". By simple location, he means first one major characteristic which refers equally to space and to time: "that material can be said to be here in space and here in time, or here in space-time, in a perfectly definite sense which does not require for its explanation any reference to other regions of space-time" (Whitehead 1967b, 49). In one word: environmental independence. And second, a minor characteristic which differentiates space and time:

as regards time, if material has existed during any period, it has equally been in existence during any portion of that period. In other words, dividing the time does not divide the material. [...] In respect to space, dividing the volume does divide the material (Whitehead 1967b, 49).

In one word: temporal independence of the successive durations. Since the division of time functions, in respect to material, so differently from the division of space, it is claimed that the "transition of time has nothing to do with the character of the material. The material is equally itself at an instant of time" (Whitehead 1967b, 49) - and at any instant of time. Whitehead adds: "Here an instant of time is conceived as in itself without transition, since the temporal transition is the succession of instants" (Whitehead 1967b, 49-50). ${ }^{20}$

Whitehead's philosophy of organism sets the destruction of simple location and external relations as its goal, and replaces it with complex (dis)location and extero-internal relations ("prehensions").

20 See also Weber 2006, 97-118. 


\subsection{Contemporaneity vs. Simultaneity}

If we focus on the relativistic issue itself, one contrast is decisive: contemporaneity is not simultaneity. The former is commonsensical, while the latter depends upon metrics, clocks, experiments and other contingencies. Whitehead argues that simultaneity should be understood independently of the speed of light:

There are certain objections to the acceptance of Einstein's definition of simultaneity, [...]. In the first place light signals are very important elements in our lives, but we cannot but feel that the signal-theory somewhat exaggerates their position. The very meaning of simultaneity is made to depend on them. There are blind people and dark cloudy nights, and neither blind people nor people in the dark are deficient in a sense of simultaneity. They know quite well what it means to bark both their shins at the same instant. In fact, the determination of simultaneity in this way is never made, and if it could be made, it would not be accurate; for we live in air and not in vacuo (Whitehead 1982, 53).

Eventually, contemporaneity has also received a metaphysical meaning within Whitehead's mature philosophy. To make a (very) long story short, the argument is the following: apparently following James's reading of Zeno and his bud theory of time and actuality, Whitehead shifts, in 1925, from a continuist phenomenology of science to what he names an epochal ontology. This amounts to revamping Leibniz, whose monads have now windows and a limited life-span (first the actual entities are subjective, becoming, or concrescing, then they perish and subsists objectively, qua being or "in transition"); if monads have windows and a life of sorts, the cosmic harmony cannot be pre-established or auto-established (actualities-subject evolve solitude to solitude), it needs the repeated action of a "limitation of antecedent selection" implemented by the past and a "principle of limitation" that Whitehead will soon call "God". ${ }^{21}$ To repeat:

21 "Value is the outcome of limitation" (Whitehead 1967b, 94); "The spatio-temporal relationship, in terms of which the actual course of events is to be expressed, is nothing else than a selective limitation within the general systematic relationships among eternal objects" (Whitehead 1967b, 161); "It has already been emphasised that an actual occasion is to be conceived as a limitation; and that this process of limitation can be still further characterised as a gradation" (Whitehead 1967b, 162); "Restriction is the price of value. There cannot be value without antecedent standards of value, to discriminate the acceptance or rejection of what is before the envisaging mode of activity. Thus, there is an antecedent limitation among values, introducing contraries, grades, and oppositions. According to this argument the fact that there is a process of actual occasions, and the fact that the occasions are the emergence of values which require such limitation, both require that the course of events should have developed amid an antecedent limitation composed of conditions, particularisation, and standards of value. Thus, as a further element in the metaphysical situation, there is required a principle of limitation" (Whitehead 1967b, 178). This is the main path towards God that process thought provides: when the 
what matters here is that the unison of (immediate) becoming, or "concrescent unison", is defined by the mutual contemporaneity of the concrescing actual entities involved, and it manifests itself as a cross-section of the universe, i.e., a duration experienced in Presentational Immediacy (Whitehead 1978, 124-125; 320).

It is the causal independence of the concrescing actualities, their constitutional privacies, that define the mutual contemporaneity, not a synchronisation effected with the help of luminous signals and frames of reference (Whitehead 1978, 61; 123). The unison does not belong to simultaneity and measured time, but to a melody of durations that require a harmonising principle.

\subsection{Threefold Root of Temporality}

Understanding together all the experiences of time requires a wider perspective. More precisely: "epistemological difficulties are only solvable by an appeal to ontology" (Whitehead 1978, 189). So far, we have seen that measured time is the expression of some features of the cosmic growth that Whitehead calls, already in Principles of Natural Knowledge (1919) and in Concept of Nature (1920) the creative advance of nature: "The forward moving time exhibits this characteristic of experience, that it is essentially action. This passage of nature or, in other words, its creative advance is its fundamental characteristic; the traditional concept is an. attempt to catch nature without its passage” (Whitehead 1982, 14).

Let us now resume the argument made in my Threefold Root of Whiteheadian Temporality (Weber 2016, 211-227). It involves revisiting the three complementary modalities of the creative advance: creativity, efficacy, and vision, reframing its Greek mirror (kairos, chronos, and aion). First of all, the very idea of time involves change, and more precisely, novelty. In Whitehead's lexicon, this is creativity aka becoming and concrescence. The bud theory is required because, as long as past causal chains hold, there is no real novelty possible, only the repetition of the same, or of a different mixture of the same. But real novelty is, by definition, totally unpredictable, wild even-whereas the world disclosed in our

decisions taken in the sepulchre of the concrescence are respectful of the cosmic tissue, it is because the initial aim has suggested the best compossibility - and because what is best for shoring up a society of actual occasions is best for one of its actualities. Depths of value, i.e., experiences of high emotional intensity, "is only possible if the antecedent facts conspire in unison. Thus, a measure of harmony in the ground is requisite for the perpetuation of depth into the future. But harmony is limitation. Thus, rightness of limitation is essential for growth of reality" (Whitehead 1926, 146). 
experience is somewhat ordered and tame. Actually, creativity is always buttressed on past events, themselves integrated in some structure (in Process and Reality, space-time is only a superficial expression of the extensive continuum). Moreover, creativity modifies that structure: "We all remember Bergson's doctrine of the élan vital and its relapse into matter. The double tendency of advance and relapse is here plainly stated" (Whitehead 1958, 29).

The second modality of the creative advance is efficacy, which names memory, being, and transition. In turn, this grants the possibility of measured time. Let us linger for a moment on efficacy, that provides a clear ontological status to the past, something that is rare enough in the history of philosophy. The late Whitehead is very clear about the nature of the past. His standpoint is, as usual, informed by common sense $\mathrm{e}^{22}$ the history of philosophy, and science; he writes:

We should balance Aristotle's-or, more rightly, Plato's-doctrine of becoming by a doctrine of perishing. When they perish, occasions pass from the immediacy of being into the not-being of immediacy. But that does not mean that they are nothing. They remain 'stubborn fact': pereunt et imputantur (Whitehead 1967a, 237).

In sum: "This is the doctrine that the creative advance of the world is the becoming, the perishing, and the objective immortalities of those things which jointly constitute stubborn fact" (Whitehead 1978, xiv). Since creativity is wild and efficacy is blind, their togetherness is likely to bring growth just as well as teratogenesis. In order to secure a positive growth, and to prevent the eternal return of the same, a third modality is required: vision, that Whitehead names god qua primordial nature, i.e., superject. Many qualifications can be given to that divinity: principle of concretion, of compossibilization, of unison. It operates through the deliverance of the initial subjective aim, securing a cosmos housing the highest intensities of experience possible. Providing the initial aim is made necessary by the constraints imposed by the privacy or independence of simultaneous concrescing actualities.

\section{Conclusion}

In conclusion, our argument has led us from the polysemiality of the notion of time to Whitehead's ontological core: the creative advance of nature. Thinking

22 Pereunt et imputantur is the inscription on old sundials in religious houses: "The hours perish and are laid to account” (Whitehead 1958b, 47). 
together rupture, structure, and adventure is a little bit like weaving again kairos, chronos, and aiôn. By doing so, we are allowed to make sense of the various experiences of time disclosed in everyday consciousness, to understand how technoscience has tremendously simplified the issue, and to clarify at what price this has made it extremely successful in its experiments and applications. It is Galilei's experimental standpoint, together with the definition of the principle of inertia, that made Newtonian science and a new cultural project possible. The price to pay was, and still is, the loss of the cosmic unison of immediacies of becoming and of the very meaning of time.

\section{References}

American Psychiatric Association (1994), Diagnostic and Statistical Manual of Mental Disorders, $4^{\text {th }}$ Edition, Washington, DC.

Arendt, Hannah (1978), The Life of the Mind, San Diego, New York, London.

Bergson, Henri (1920), Mind-Energy. Lectures and Essays, New York.

Bergson, Henri (1965), Duration and Simultaneity: with Reference to Einstein's Theory, La

Salle, Indianapolis.

Bourdieu, Pierre (1994), Raisons pratiques. Sur la théorie de l'action, Paris.

Darwin Charles (1859), On the origin of species by means of natural selection, London.

Desmet, Ronald (2010a), “On the Need to Interpret General Relativity”, in: Process Studies Supplements 15, 1-65.

Desmet, Ronald (2010b), “Whitehead's Relativity”, in: Michel Weber/Ronald Desmet (eds.), Whitehead. The Algebra of Metaphysics. Applied Process Metaphysics Summer Institute Memorandum, Louvain-la-Neuve, 365-374.

Emmet, Dorothy M. (1948), “A. N. Whitehead: The Last Phase”, in: Mind 57, 265-274.

Griffin, David R. (1977), “Whitehead's Philosophy and Some General Notions of Physics and Biology”, in: John B. Cobb/David R. Griffin (eds.), Mind in Nature. Essays on the Interface of Science and Philosophy, Washington DC, 122-134.

Habermas, Jürgen (1968), Technik und Wissenschaft als Ideologie, Frankfurt am Main. Heidegger, Martin (1967), What is a Thing?, Chicago.

Hottois, Gilbert (1984), Le Signe et la technique. La philosophie à l'épreuve de la technique, Paris.

James, William (1950), The Principles of Psychology, New York.

Jonas, Hans (1966), The Phenomenon of Life: Toward a Philosophical Biology, Chicago, London.

Kant, Immanuel (1996), “An answer to the question: What is enlightenment?”, in: Mary Gregor/Allen W. Wood (eds.), Practical Philosophy, in: The Cambridge Edition of the Works of Immanuel Kant, Cambridge, 11-22.

Maxwell, James Clerk (1954), A Treatise on Electricity and Magnetism, New York. Minkowski, Eugéne (1970), Lived Time: Phenomenological and psychopathological studies, Evaston, IL. 
Musso, Pierre (2017), La Religion industrielle. Monastère, Manufacture, Usine. Une généalogie de l'entreprise, Paris.

Pöppel, Ernst (1988), Mindworks: Time and Conscious Experience, New York.

Russell, Bertrand (1911), Letter of September 3, in: Archives, McMaster University: Hamilton, Ontario - quoted in Lowe, Victor (1985), Alfred North Whitehead. The Man and His Work, vol. I, 1861-1910, Baltimore.

Russell, Bertrand (1956), Portraits from Memory and Other Essays, New York.

Sherrington, Charles S. (1940), Man on his Nature. The Gifford Lectures, Edinburgh 1937-1938, Cambridge.

Sherrington, Charles S. (1947), The Integrative Action of the Nervous System, Cambridge.

Spencer, Herbert (1855), Principles of Psychology, London.

Weber, Michel (2006), “The Organic Turn: From Simple Location to Complex (dis)location”, in: François Beets/Michel Dupuis/Michel Weber (eds.), Alfred North Whitehead's Science and the Modern World, Frankfurt/Lancaster, 97-118.

Weber, Michel (2016), “The Threefold Root of Whiteheadian Temporality”, in: KronoScope 16 (2), 211- 227.

Whitehead, Alfred N. (1898), A Treatise on Universal Algebra, Cambridge.

Whitehead, Alfred N. (1906a), "On Mathematical Concepts of the Material World", in: Philosophical Transactions of the Royal Society of London 205 (1906), 465-525.

Whitehead, Alfred N. (1906b), The Axioms of Projective Geometry, Cambridge.

Whitehead, Alfred N. (1907), The Axioms of Descriptive Geometry, Cambridge.

Whitehead, Alfred N. (1910), Principia Mathematica, London.

Whitehead, Alfred N. (1916), "La théorie relationniste de l'espace", in : Revue de Métaphysique et de Morale 23 (3), 423-445.

Whitehead, Alfred N. (1917), The organization of thought educational and scientific, London.

Whitehead, Alfred N. (1922), The Principle of Relativity, Cambridge.

Whitehead, Alfred N. (1958a), The Function of Reason, Boston.

Whitehead, Alfred N. (1958b), Symbolism: Its Meaning and Effect, New York.

Whitehead, Alfred N. (1958c), An Introduction to Mathematics, Cambridge.

Whitehead, Alfred N. (1964), The Concept of Nature, Cambridge.

Whitehead, Alfred N. (1967), Adventures of Ideas, New York.

Whitehead, Alfred N. (1967a), The Aims of Education, New York.

Whitehead, Alfred N. (1967b), Science and the Modern World, New York.

Whitehead, Alfred N. (1968), Modes of Thought, New York.

Whitehead, Alfred N. (1978), Process and Reality. An essay on cosmology, New York.

Whitehead, Alfred N. (1982), Principles of Natural Knowledge, New York.

Whitehead, Alfred N. (2011), Religion in the Making, Cambridge.

Wundt, Wilhelm (1896), Grundriss der Psychologie, Leipzig. 